\title{
' $\mathrm{CO}_{2}$-ligated' cytochrome $\mathrm{C}$ oxidase: characterization and comparison with the $\mathrm{Cl}^{-}$-ligated enzyme
}

\author{
A. John MOODY, ${ }^{\star} \ddagger$ Matthew RICHARDSON, ${ }^{*}$ Jeremy P. E. SPENCER, ${ }^{\star}$ Ulrich BRANDT $\dagger$ and Peter R. RICH ${ }^{\star}$ \\ *Glynn Research Institute, Glynn, Bodmin PL30 4AU, U.K. and †Gustav-Emden-Zentrum der Biologischen Chemie, Klinikum der Johann Wolfgang Goethe-Universität, \\ Frankfurt am Main, Germany
}

A form of fully oxidized bovine heart cytochrome $c$ oxidase that is induced by $\mathrm{CO}_{2} / \mathrm{HCO}_{3}^{-}$is described. The ligand-binding properties of this form are similar to those of $\mathrm{Cl}^{-}$-ligated oxidase [Moody, Cooper and Rich (1991) Biochim. Biophys. Acta 1059, 189-207]. Both bind cyanide at a rate $\left(0.2 \mathrm{M}^{-1} \cdot \mathrm{s}^{-1}\right.$ at $\left.\mathrm{pH} 6.5\right)$ intermediate between the rate of binding to the fast and slow forms of the enzyme, and binding of formate to both is almost undetectable. They are also similar in showing poor reactivity with $\mathrm{H}_{2} \mathrm{O}_{2}$, or with $\mathrm{CO}$ in the presence of $\mathrm{O}_{2}$, which, with fast oxidase, induce the formation of the 'ferryl' and 'peroxy' states respectively. However, there is a clear difference in the nearu.v./visible absorption spectra of the two forms; that induced by $\mathrm{CO}_{2} / \mathrm{HCO}_{3}{ }^{-}$has a Soret maximum at $427 \mathrm{~nm}$ whereas $\mathrm{Cl}^{-}$ligated oxidase has a Soret maximum similar to that of fast oxidase at about $424 \mathrm{~nm}$. It appears that both $\mathrm{CO}_{2} / \mathrm{HCO}_{3}{ }^{-}$and $\mathrm{Cl}^{-}$are members of a class of ligands that lowers the reactivity of the binuclear centre but does not impede intramolecular electron transfer from haem $a$ to the binuclear centre, unlike the putative endogenous ligand responsible for slow oxidase.

\section{INTRODUCTION}

Cytochrome $c$ oxidase (EC 1.9.3.1), the terminal component of the mammalian respiratory chain, catalyses the four-electron reduction of dioxygen. Electrons are transferred from cytochrome $c$, on the cytosolic side of the inner mitochondrial membrane, via $\mathrm{Cu}_{\mathrm{A}}$ and haem $a$, to a binuclear metal centre, consisting of haem $a_{3}$ and $\mathrm{Cu}_{\mathrm{B}}$, where oxygen is bound and reduced. The reduction of oxygen is coupled to proton translocation from the matrix to the cytosol, with an average stoichiometry of $1 \mathrm{H}^{+} / \mathrm{e}[1,2]$.

The problem of heterogeneity in fully oxidized preparations of bovine heart cytochrome $c$ oxidase has long been recognized [3]. Fast oxidase, which has a Soret absorption maximum at $424 \mathrm{~nm}$, is thought to be the form of the fully oxidized enzyme that is present in situ in the inner mitochondrial membrane, whereas slow oxidase, which has a Soret maximum at $417 \mathrm{~nm}$, is found to accumulate during and after purification if the $\mathrm{pH}$ is low [4,5]. In contrast to fast oxidase, the binuclear centre of slow oxidase is difficult to reduce and shows poor reactivity with inhibitory ligands such as cyanide and $\mathrm{CO}[4,6]$. Because the spectral and ligand-binding properties of enzyme ligated with another inhibitory ligand, formate, are almost identical to those of slow oxidase, the idea has arisen that the differences between fast and slow oxidase lie in a rearrangement of the binuclear centre in which an endogenous ligand, e.g. a carboxylate residue, occupies a similar spatial position to formate $[5,7]$. We have previously reported a further form of fully oxidized cytochrome oxidase that is induced when fast oxidase is incubated with $\mathrm{Cl}^{-}$[5]. In the present paper we describe another form that is induced when fast oxidase is incubated with $\mathrm{CO}_{2} / \mathrm{HCO}_{3}{ }^{-}$, and compare this with that induced by $\mathrm{Cl}^{-}$.

\section{MATERIALS AND METHODS}

\section{Enzyme preparations}

Two of the cytochrome oxidase preparations (Preparations 1 and
2) were made from bovine heart in the same way as Preparation $\mathrm{C}$ in Moody et al. [5]. This type of preparation, particularly when fresh, is essentially in the fast form, but Preparation 1, when used, contained $14 \%$ slow form. A third cytochrome oxidase preparation, Preparation 3, made by the method of Brandt et al. [8], was also used, and this contained no detectable slow form. All three preparations were stored in liquid nitrogen before use. Enzyme concentrations were estimated using $A_{422} \sim$ $160 \mathrm{mM}^{-1} \cdot \mathrm{cm}^{-1}[9]$.

\section{Generation of solid and gaseous $\mathrm{CO}_{2}$}

Solid $\mathrm{CO}_{2}$ was made using a Frigimat Junior dry-ice maker from Aldrich Chemical Co. Ltd. (Gillingham, Dorset, U.K.). We generated $\mathrm{CO}_{2}$ gas by sublimation of the solid in a Thunberg tube connected to Esco Butyl XX rubber tubing (Bibby Sterilin Ltd., Aldershot, Hampshire, U.K.). The gas was moistened by bubbling through water in line, and the supply was regulated by diverting part of the flow to an exhaust.

\section{Incubation of cytochrome oxidase under a $\mathrm{CO}_{2}$ atmosphere}

Medium (200 mM Tris $/ 200 \mathrm{mM}$ Hepes, pH 8.0, containing $0.5 \mathrm{mM}$ potassium EDTA) was placed at room temperature $\left(18-22^{\circ} \mathrm{C}\right)$ in a glass vessel fitted with a silicone rubber bung. The inlet for the $\mathrm{CO}_{2}$ supply was formed by a hypodermic needle pushed through the bung and the outlet by a small vent in the bung. The system was flushed with gas for $10 \mathrm{~min}$, during which time the medium was stirred. Stock enzyme solution (100$200 \mu \mathrm{M}$ ) was then diluted 10 -fold in the medium, after which a slight positive pressure of $\mathrm{CO}_{2}$ was maintained in the reaction vessel for $90 \mathrm{~min}$. Samples could be removed during this time via the vent. The reaction vessel was then sealed for the remainder of the incubation. After a total of $18 \mathrm{~h}$ under the $\mathrm{CO}_{2}$ atmosphere, the enzyme was concentrated 5-10-fold using a Centriprep-30 concentrator (Amicon Ltd., Stonehouse, Gloucestershire, U.K.) and stored in liquid nitrogen before use.

Although the $\mathrm{pH}$ of the medium starts at 8.0 , this decreases as 
$\mathrm{CO}_{2}$ dissolves and is hydrated $\left(\mathrm{CO}_{2}+\mathrm{H}_{2} \mathrm{O} \rightleftharpoons \mathrm{H}_{2} \mathrm{CO}_{3}\right.$, followed by $\left.\mathrm{H}_{2} \mathrm{CO}_{3}+\mathrm{OH}^{-} \rightleftharpoons \mathrm{HCO}_{3}{ }^{-}+\mathrm{H}_{2} \mathrm{O}[10]\right)$. Over the first $10 \mathrm{~min}$ while the system is being flushed with gas, and before the enzyme is added, the $\mathrm{pH}$ decreases to 7.3. There is a further decrease to 6.8 over the first 90 min of incubation after the enzyme is added, i.e. while the slight positive pressure of $\mathrm{CO}_{2}$ is being maintained, and thereafter when the vessel is sealed the $\mathrm{pH}$ is constant. Hence, during incubations of the enzyme with $\mathrm{CO}_{2}$ the $\mathrm{pH}$ is in the range 6.8-7.3. The concentration of dissolved $\mathrm{CO}_{2}$ when the medium is saturated is $\sim 40 \mathrm{mM}$ [11] and the concentration of $\mathrm{HCO}_{3}{ }^{-}$in equilibrium varies from $\sim 80 \mathrm{mM}$ at pH 6.8 to $250 \mathrm{mM}$ at $\mathrm{pH} 7.3$ taking the apparent $\mathrm{p} K_{\mathrm{a}}$ for the equilibrium to be 6.5 [10].

\section{Cyanide and formate binding kinetics}

The kinetics of cyanide and formate binding at $20^{\circ} \mathrm{C}$ were monitored using wavelength pairs in the Soret region: $\Delta A_{432-412}$ or $\Delta A_{428-410}$ were used interchangeably. These wavelengths were obtained by reference to binding spectra (e.g. cyanide [12] and formate [13]). Optical measurements were done either in a dualwavelength spectrophotometer (Sigma Instruments, Berlin) or in an in-house-constructed single-beam spectrophotometer, under computer control, in which case for dual-wavelength measurements the monochromator was cycled between the wavelengths as described before [5].

\section{Reagents}

All reagents were supplied either by Sigma (Poole, Dorset, U.K.) or by Merck Ltd. (Lutterworth, Leicestershire, U.K.) and were

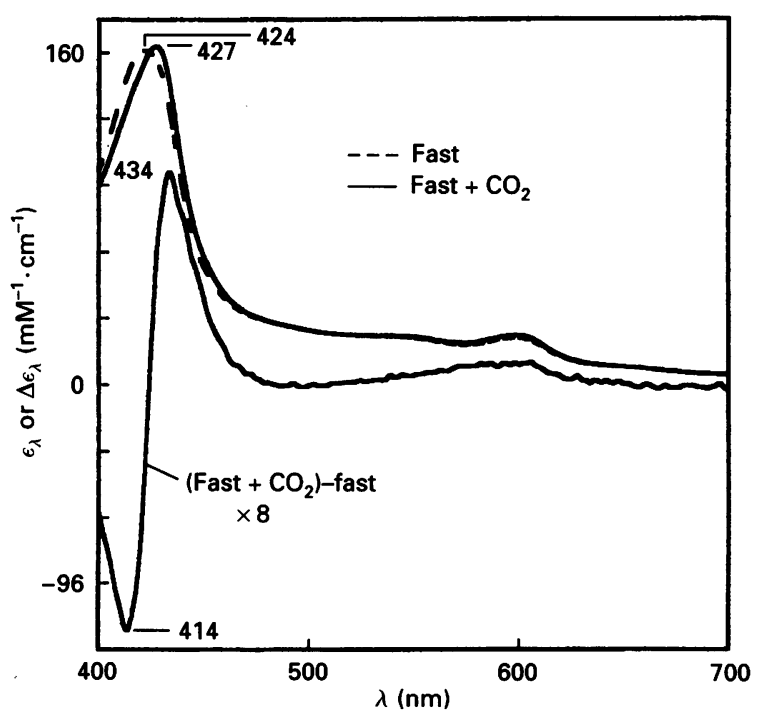

Figure 1 The effect of incubation under a $\mathrm{CO}_{2}$ atmosphere on the nearu.v./visible absorption spectrum of cytochrome oxidase

Fast cytochrome oxidase was incubated at $20^{\circ} \mathrm{C}$ under a $\mathrm{CO}_{2}$ atmosphere for $18 \mathrm{~h}$ as described in the Materials and methods section. The absolute spectra (top of figure) are of control enzyme $(--)$ and $\mathrm{CO}_{2}$-treated enzyme ( $\longrightarrow$ diluted to $2-3 \mu \mathrm{M}$ in $50 \mathrm{mM}$ potassium phosphate buffer, $\mathrm{pH} 6.5$, containing $0.5 \mathrm{mM}$ potassium EDTA, $40 \mu \mathrm{M}$ potassium ferricyanide and $0.05 \%$ $n$-octyl $\beta$-o-glucopyranoside. The difference between these spectra (bottom of figure) has been enlarged 8-fold. of Analar or similar grade, except for $\mathrm{CO}_{2}(99.987 \%$ pure) which was supplied by BOC Ltd. (Bristol, U.K.).

\section{RESULTS}

\section{The effects of incubation with $\mathrm{CO}_{2} / \mathrm{HCO}_{3}{ }^{-}$on cytochrome $\mathrm{C}$ oxidase}

\section{Spectral changes}

Incubation with $\mathrm{CO}_{2} / \mathrm{HCO}_{3}^{-}$at $\mathrm{pH} 6.5-8.0$, either by adding solid potassium bicarbonate or using a $\mathrm{CO}_{2}$ atmosphere, leads to changes both in the ligand-binding properties and in the nearu.v./visible absorption spectrum of cytochrome oxidase. Figure 1 shows the effect of incubation of fast oxidase under a $\mathrm{CO}_{2}$ atmosphere on the spectrum of the enzyme. The Soret absorption maximum shifts from 424 to $427 \mathrm{~nm}$, and the resulting difference spectrum has a trough at $414 \mathrm{~nm}$ and a peak at $434 \mathrm{~nm}$. The red-shift in the Soret maximum is accompanied by slight changes in absorbance in the visible region (for the maximum $\Delta \mathrm{A}, \epsilon<1.5 \mathrm{mM}^{-1} \cdot \mathrm{cm}^{-1}$ ), while the ' $655 \mathrm{~nm}$ ' chargetransfer band associated with high-spin ferric haem $a_{3}$ is unaffected by the treatment.

\section{Cyanide binding}

The spectral changes occur together with a decrease in the extent of the fast phase of cyanide binding by the enzyme (Figure 2) and the appearance of a new phase with slower kinetics. The pseudo-first-order rate constant, $k^{\prime}(20 \mathrm{mM} \mathrm{KCN}, \mathrm{pH} 8.0)$, obtained by curve-fitting to the data in Figure 2 is $0.0040 \pm$ $0.0001 \mathrm{~s}^{-1}$ (mean \pm S.E.M., $n=2$ ). This is equivalent to a secondorder rate constant of $\sim 0.2 \mathrm{M}^{-1} \cdot \mathrm{s}^{-1}$, i.e. intermediate between the rate constants for cyanide binding to the fast and slow oxidase (1-2 and $0.01-0.02 \mathrm{M}^{-1} \cdot \mathrm{s}^{-1}$ respectively).

The rate of cyanide binding in the phase with intermediate kinetics induced by $\mathrm{CO}_{2} / \mathrm{HCO}_{3}^{-}$shows no significant $\mathrm{pH}$ dependence, values for $k^{\prime}$ of $0.0040 \pm 0.0004 \mathrm{~s}^{-1}(n=3)$ and $0.0038 \pm 0.0005 \mathrm{~s}^{-1}(n=3)$ being obtained at $\mathrm{pH} 6.5$ and 8.0 respectively for the same batch of treated enzyme (using $20 \mathrm{mM}$ $\mathrm{KCN}$ as in Figure 2). Similar changes are seen when $\mathrm{HCO}_{3}{ }^{-}$is used in place of $\mathrm{CO}_{2}$, and these changes are retained even when the excess $\mathrm{CO}_{2} / \mathrm{HCO}_{3}{ }^{-}$is removed by passage of the enzyme through a Sephadex G-25 column. They are also found when fast oxidase is stored frozen for $24 \mathrm{~h}$ in solid $\mathrm{CO}_{2}$, unless a gas-tight container is used, although in this case there is also some spontaneous conversion to the slow form.

\section{Formate binding}

$\mathrm{CO}_{2} / \mathrm{HCO}_{3}{ }^{-}$also induces distinct changes in the formate-binding properties of cytochrome oxidase (Figure 3). Fast oxidase shows two phases of formate binding, which differ by $\sim 10$-fold in rate ( $k^{\prime}$ with $20 \mathrm{mM}$ formate is $\sim 0.1 \mathrm{~s}^{-1}$ and $\sim 0.01 \mathrm{~s}^{-1}$ respectively at $\mathrm{pH}$ 6.5) [5]. Both of these phases decrease in extent on incubation with $\mathrm{CO}_{2} / \mathrm{HCO}_{3}{ }^{-}$, and they appear to be replaced by a third, much slower $\left(k^{\prime}<0.0002 \mathrm{~s}^{-1}\right)$, phase.

\section{Other reactions}

Although difficult to assess quantitatively, it is clear that treatment of cytochrome oxidase with $\mathrm{CO}_{2} / \mathrm{HCO}_{3}{ }^{-}$affects the reactivity of the enzyme towards both $\mathrm{H}_{2} \mathrm{O}_{2}$ and $\mathrm{CO}$. High concentrations of $\mathrm{H}_{2} \mathrm{O}_{2}$ convert fast oxidase, via the 'peroxy' form, almost completely to the 'ferryl' form [15], whereas $\mathrm{CO}$, in the presence of oxygen, converts fast oxidase almost completely 

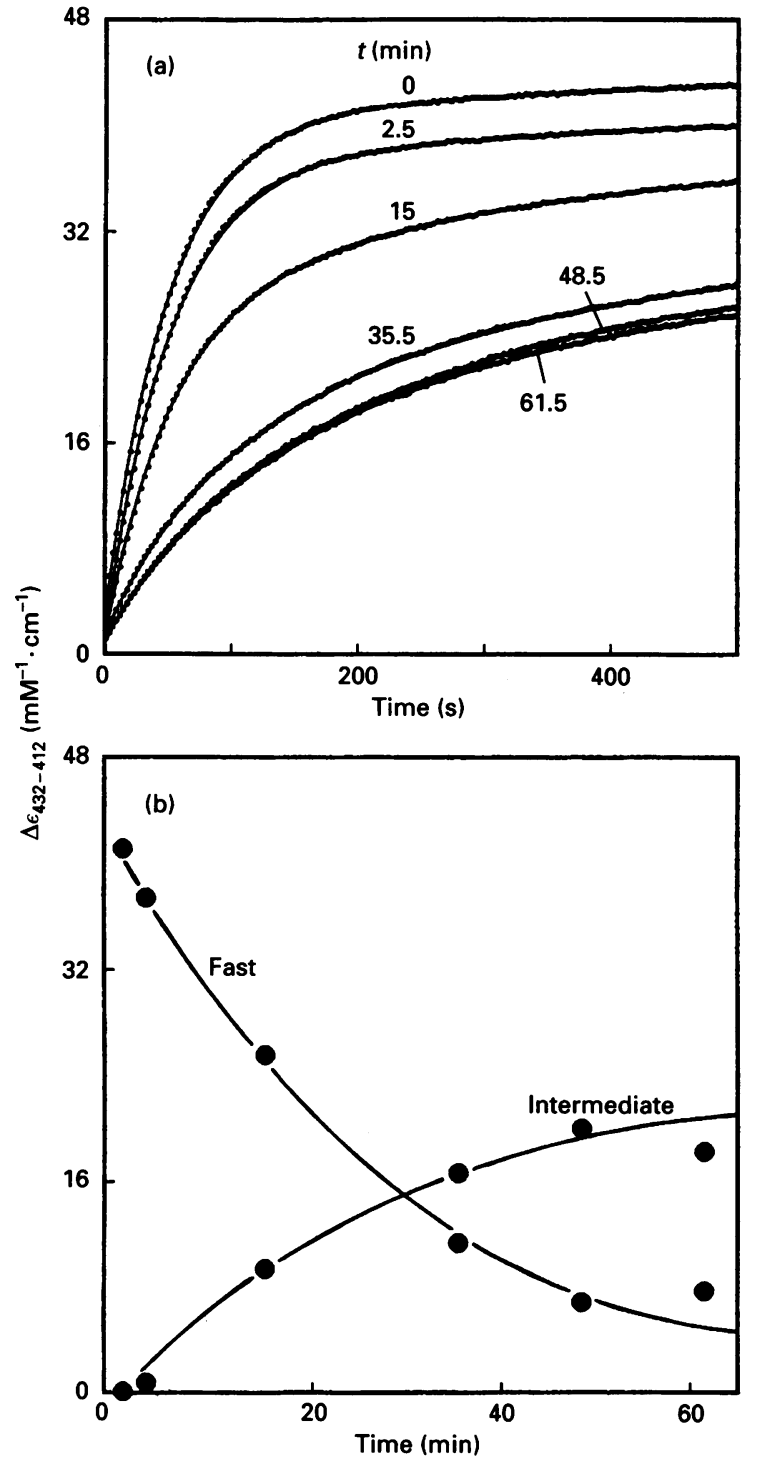

Figure 2 The effect of incubation under a $\mathrm{CO}_{2}$ atmosphere on the cyanidebinding kinetics of cytochrome oxidase

Fast cytochrome oxidase was incubated at $18^{\circ} \mathrm{C}$ under a $\mathrm{CO}_{2}$ atmosphere as described in the Materials and methods section. The starting $\mathrm{pH}$ was 7.3 , and this decreased to 6.8 during the course of the incubation. (a) Time courses of cyanide binding to cytochrome oxidase after incubation of the enzyme with $\mathrm{CO}_{2}$ for the times $(t)$ indicated. Enzyme samples were diluted to 2-3 $\mu \mathrm{M}$ with $200 \mathrm{mM}$ Tris/200 mM Hepes, pH 8.0, containing $0.5 \mathrm{mM}$ potassium EDTA (the assay $\mathrm{pH}$ was 7.7-8.0), and the reaction was started by addition of $20 \mathrm{mM} \mathrm{KCN}$. In each case the dead time before measurements were started was 5-10 s. (b) The extents of the fast and intermediate phases of cyanide binding versus incubation time. These extents were obtained by fitting two independent exponential phases and a linear phase to the time courses in (a) using the simplex method [14]. The linear phase was included because the enzyme preparation used here contained a significant level of the slow form (see the Introduction and Materials and methods sections ). $K$ for the slower exponential phase was constrained to $0.0040 \mathrm{~s}^{-1}$, i.e. the average obtained from free fits to the time courses at 48.5 and $61.5 \mathrm{~min}$.

to the 'peroxy' form [16]. Both of these forms have characteristic spectral features in the visible region; e.g. the difference spectrum of the 'ferryl' form versus the fast form has a peak at $580 \mathrm{~nm}$, whereas the difference spectrum of the 'peroxy' form versus the fast form has a peak at $607 \mathrm{~nm}$ (Figure 4, B2 and A2 respectively). As we have seen, $\mathrm{CO}_{2} / \mathrm{HCO}_{3}^{-}$induces little change in the

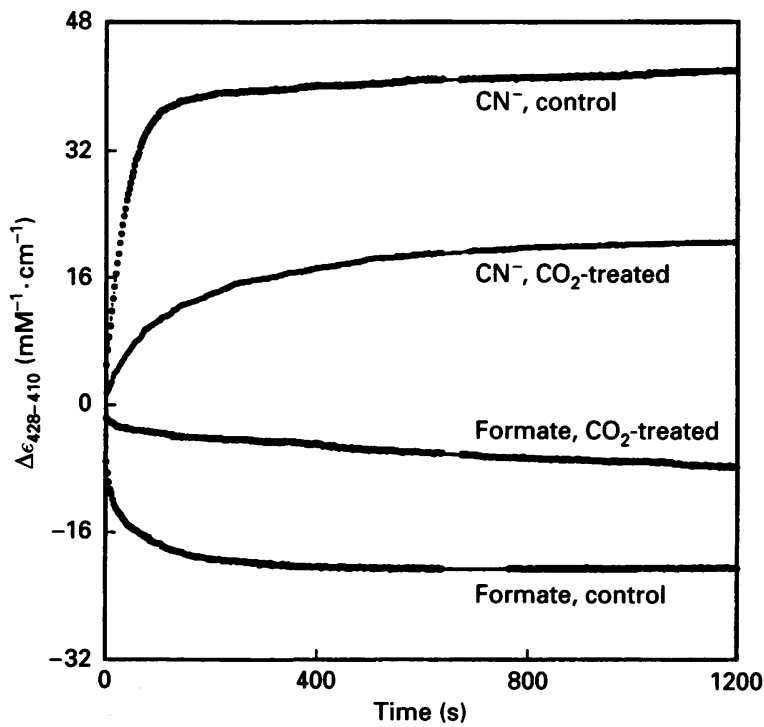

Figure 3 A comparison of the cyanide- and formate-binding kinetics of cytochrome oxidase incubated under a $\mathrm{CO}_{2}$ atmosphere with those of control enzyme

Fast cytochrome oxidase was incubated at $20^{\circ} \mathrm{C}$ under a $\mathrm{CO}_{2}$ atmosphere for $18 \mathrm{~h}$ as described in the Materials and methods section. Either this enzyme or untreated control enzyme (as indicated) was diluted to $2-3 \mu \mathrm{M}$ in $50 \mathrm{mM}$ potassium phosphate containing $0.5 \mathrm{mM}$ potassium EDTA and $40 \mu \mathrm{M}$ potassium ferricyanide. For the cyanide-binding kinetics the $\mathrm{pH}$ was 7.0 and the reaction was started by adding $20 \mathrm{mM} \mathrm{KCN}$; for the formate-binding kinetics the $\mathrm{pH}$ was 6.5 and the reaction was started by adding $20 \mathrm{mM}$ potassium formate. The dead time in each case was $5-10 \mathrm{~s}$.

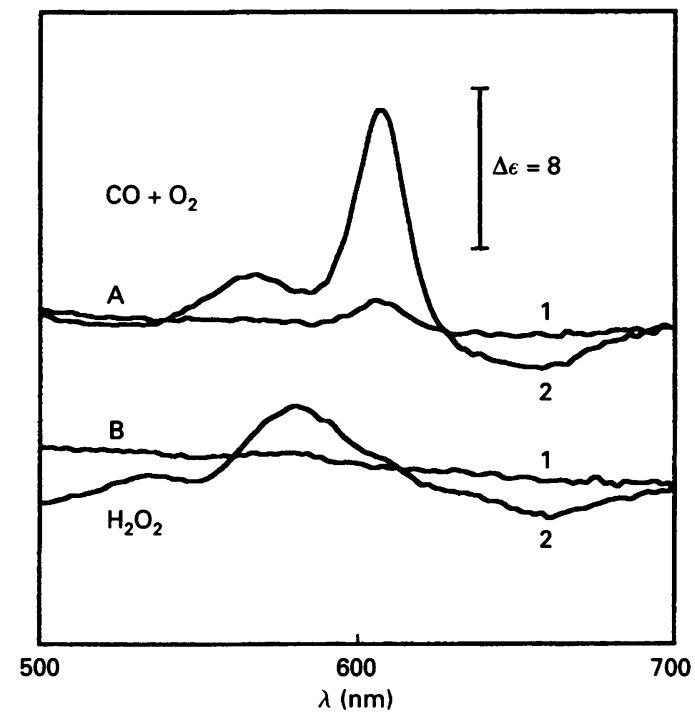

Figure 4 A comparison of the effects of $\mathrm{CO}$ and $\mathrm{H}_{2} \mathrm{O}_{2}$ on aerobic cytochrome oxidase that has been incubated under a $\mathrm{CO}_{2}$ atmosphere with those of control enzyme

Fast cytochrome oxidase was incubated at $20^{\circ} \mathrm{C}$ under a $\mathrm{CO}_{2}$ atmosphere for $18 \mathrm{~h}$ as described in the Materials and Methods section. Either this enzyme (1) or untreated control enzyme (2) was diluted to $2-3 \mu \mathrm{M}$ in $200 \mathrm{mM}$ Tris/200 mM Hepes, pH 8.0, containing $0.5 \mathrm{mM}$ potassium EDTA and $40 \mu \mathrm{M}$ potassium ferricyanide. After $4 \mathrm{~min}$ the enzyme samples were treated either by directing a gentle stream of $\mathrm{CO}$ on the surface of the sample for $30 \mathrm{~s}$ while agitating it (A) or by adding $0.8 \mathrm{mM} \mathrm{H}_{2} \mathrm{O}_{2}$ (B). The Figure shows the differences between the spectra after treatment ( 5 min after for $\mathrm{CO} ; 2$ min after for $\mathrm{H}_{2} \mathrm{O}_{2}$ ) minus those before treatment. 

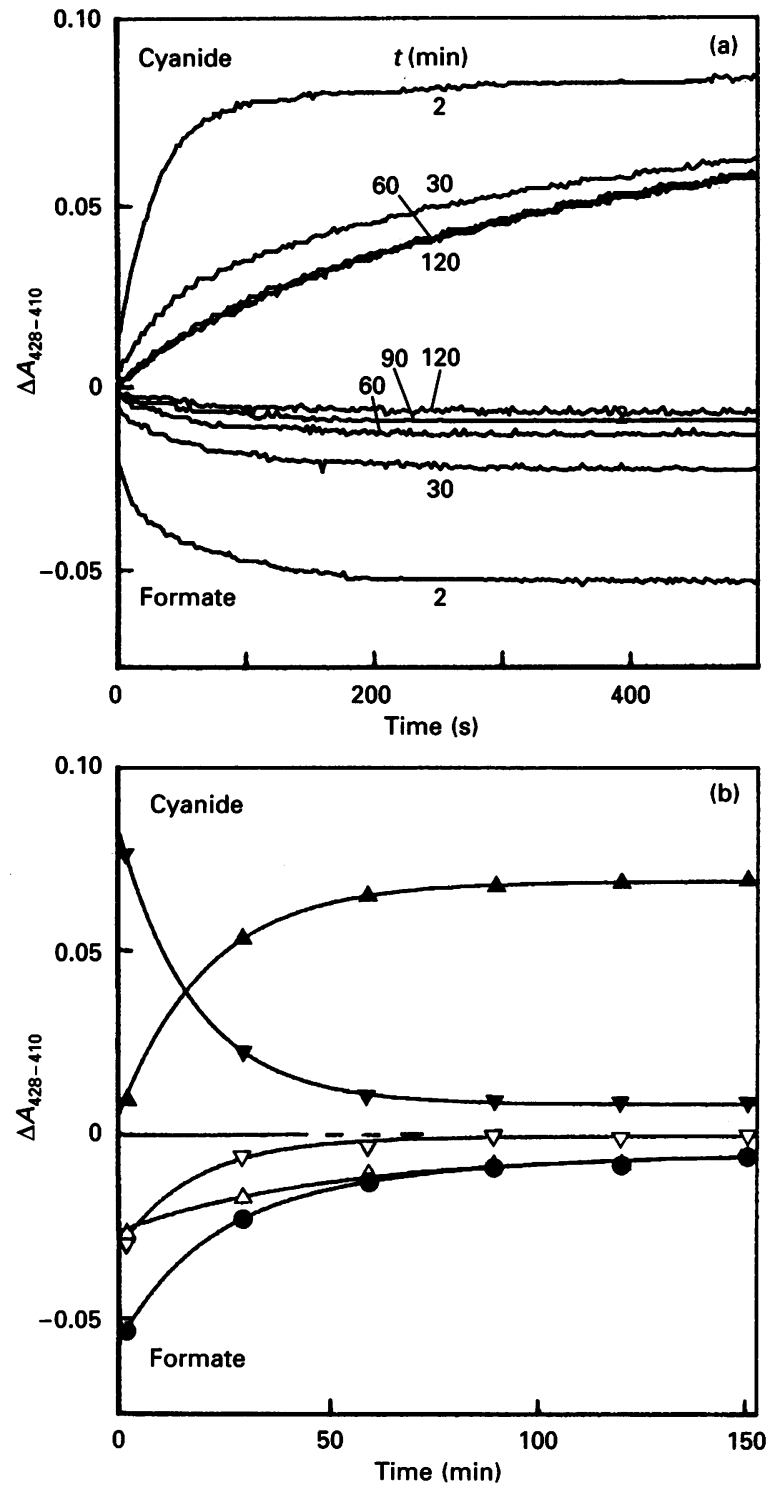

Figure 5 The effect of incubation with $\mathrm{Cl}^{-}$on the cyanide- and formatebinding kinetics of cytochrome oxidase

Fast cytochrome oxidase (Preparation B) was diluted to $1.7 \mu \mathrm{M}$ in $50 \mathrm{mM}$ potassium phosphate, $\mathrm{pH} 6.5$, containing $0.5 \mathrm{mM}$ potassium EDTA, $50 \mu \mathrm{M}$ potassium ferricyanide, 120 i.u. $/ \mathrm{ml}$ catalase and $0.5 \mathrm{M} \mathrm{KCl}$, and incubated at $22{ }^{\circ} \mathrm{C}$. (a) Time courses of cyanide and formate binding to cytochrome oxidase after incubation of the enzyme with $\mathrm{Cl}^{-}$. Samples of the diluted enzyme were taken at the times indicated and the reaction started by addition of $20 \mathrm{mM}$ potassium cyanide or formate. The dead time in each case is 5-10 s. (b) The extents of the fast $(\boldsymbol{\Lambda})$ and intermediate $(\boldsymbol{\nabla})$ phases of cyanide binding; the extents of the fast $(\nabla)$ and slow $(\triangle)$ phases of formate binding; and the total extent of formate binding $(\mathbf{)}$ versus incubation time. These extents were obtained by fitting two independent exponential phases to the time courses in (a) using the simplex method [15]. $k^{\prime}$ for the slower exponential phase of cyanide binding was constrained to $0.0025 \mathrm{~s}^{-1}$, i.e. that obtained from a free fit to the time course at $30 \mathrm{~min}$. For the formate binding data $k^{\prime}$ was constrained to $0.124 \mathrm{~s}^{-1}$ for the fast phase, and to $0.014 \mathrm{~s}^{-1}$ for the slow phase, i.e. those values obtained from a free fit to the time course at $2 \mathrm{~min}$.

spectrum in the visible region. We would therefore expect to still be able to see the characteristic features of the 'peroxy' and 'ferryl' forms of the enzyme. However, the near absence of these features in the difference spectra shown in Figure 4 (A1 and B1,

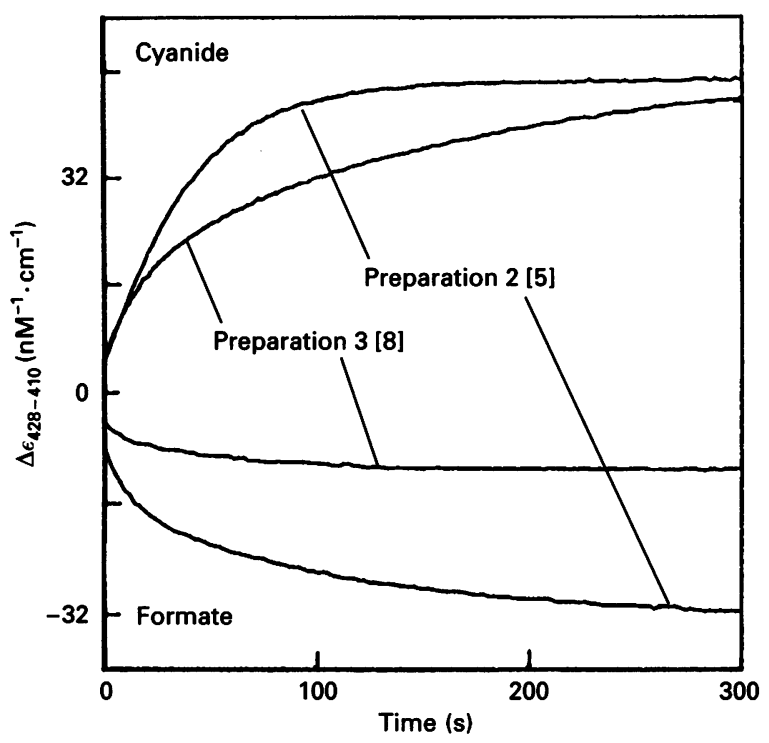

Figure 6 A comparison of the cyanide- and formate-binding kinetics of fast cytochrome oxidase prepared by the method of Moody et al. [5] (Preparation 2) with those of cytochrome oxidase prepared by the method of Brandt et al. [8] (Preparation 3)

Stock enzyme was diluted to $2-3 \mu \mathrm{M}$ in $50 \mathrm{mM}$ potassium phosphate, $\mathrm{pH} 6.5$, containing $0.5 \mathrm{mM}$ potassium EDTA and $40 \mu \mathrm{M}$ potassium ferricyanide. For the cyanide-binding kinetics the reaction was started by adding $20 \mathrm{mM} \mathrm{KCN}$; for the formate-binding kinetics the reaction was started by adding $20 \mathrm{mM}$ potassium formate. The dead time in each case was 5-10 s.

which correspond to the control spectra A2 and B2 respectively) shows that these reactions are almost absent in enzyme that has been incubated with $\mathrm{CO}_{2} / \mathrm{HCO}_{3}{ }^{-}$.

A characteristic of fast cytochrome oxidase is that both haems are reduced rapidly and essentially simultaneously by $20 \mathrm{mM}$ dithionite (at $20^{\circ} \mathrm{C}$ ). With slow oxidase, under the same conditions, haem $a$ is still reduced rapidly, but a period of $5-10 \mathrm{~min}$ is required for the complete reduction of haem $a_{3}$ [5]. The dithionite-reduction kinetics of $\mathrm{CO}_{2} / \mathrm{HCO}_{3}{ }^{-}$-treated oxidase appear to be no different to those of fast oxidase, at least with $20 \mathrm{mM}$ dithionite.

\section{Comparison with the effects of $\mathrm{Cl}^{-}$on ligand binding by cytochrome $c$ oxidase}

We have already reported that incubation of fast oxidase with $\mathrm{Cl}^{-}$leads to the appearance of a form of the enzyme that binds cyanide with intermediate kinetics, but which is spectrally similar to fast oxidase [5]. The rate of cyanide binding to $\mathrm{Cl}^{-}$-ligated oxidase at $\mathrm{pH} 6.5$ is similar to the rate of cyanide binding to the form of the enzyme induced by incubation with $\mathrm{CO}_{2} / \mathrm{HCO}_{3}{ }^{-}$that is described here. However, cyanide binding to $\mathrm{Cl}^{-}$-ligated oxidase is $\mathrm{pH}$-dependent, increasing almost 3-fold in rate between pH 6.5 and 8.0 (results not shown, but see Table II in [5]), whereas cyanide binding to the $\mathrm{CO}_{2} / \mathrm{HCO}_{3}{ }^{-}$-induced form is not. To allow further comparison of the properties of the two forms of the enzyme, we have examined the effect of $\mathrm{Cl}^{-}$on the formatebinding kinetics of fast oxidase. Figure 5(a) shows the effect of preincubation with $0.5 \mathrm{M} \mathrm{Cl}^{-}$at $\mathrm{pH} 6.5$ on the cyanide- and formate-binding kinetics of fast cytochrome oxidase. As summarized in Figure 5(b), fast oxidase is converted almost entirely to the $\mathrm{Cl}^{-}$-ligated form $\left(k^{\prime} 0.0025 \mathrm{~s}^{-1}\right.$ with $\left.20 \mathrm{mM} \mathrm{KCN}, \mathrm{pH} 7.0\right)$ after incubation for $90 \mathrm{~min}$. The changes in the formate-binding kinetics accompanying this conversion are marked; there is an 
Table 1 The properties of $\mathrm{CO}_{2} / \mathrm{HCO}_{3}{ }^{-}$-treated cytochrome oxidase compared with those of the fast, slow and $\mathrm{Cl}^{-}$-ligated forms

\begin{tabular}{|c|c|c|c|c|}
\hline Property & $\mathrm{CO}_{2} / \mathrm{HCO}_{3}^{-}$ & $\mathrm{Cl}^{-}$ & Fast & Slow \\
\hline $\begin{array}{l}\text { Soret } \lambda_{\max }(\mathrm{nm}) \\
\text { Cyanide binding }\end{array}$ & 427 & $422-424$ & 424 & 417 \\
\hline $\begin{array}{l}k^{\prime}\left(\mathrm{M}^{-1} \cdot \mathrm{s}^{-1}\right) \\
\mathrm{pH} \text { dependency }\end{array}$ & $\begin{array}{l}0.2 \\
\text { None }\end{array}$ & $\begin{array}{l}0.1-0.2 \text { at } \mathrm{pH} 6.5 \\
\text { Positive }\end{array}$ & $\begin{array}{l}1-2 \\
\text { Negative }\end{array}$ & $\begin{array}{l}0.01-0.02 \\
\text { None }\end{array}$ \\
\hline Formate binding & & & & \\
\hline$k^{\prime}\left(M^{-1} \cdot s^{-1}\right)$ & $<0.01$ at pH 6.5 & Not detectable & $\begin{array}{l}\text { Biphasic, } 5 \text { and } 0.5 \\
\text { at pH } 6.5\end{array}$ & Unknown \\
\hline Reaction with $\mathrm{H}_{2} \mathrm{O}_{2}$ & No & Unknown & Yes & No \\
\hline Reaction with $\mathrm{CO}+\mathrm{O}_{2}$ & No & No & Yes & No \\
\hline $\begin{array}{l}\text { Haem reduction with } \\
20 \mathrm{mM} \text { dithionite }\end{array}$ & Fast and simultaneous & Fast and simultaneous & Fast and simultaneous & $\begin{array}{l}\text { Haem } a \text { fast; } \\
\text { haem } a_{3} \text {, } \\
k^{\prime} \sim 0.01 \mathrm{~s}^{-1}\end{array}$ \\
\hline
\end{tabular}

almost complete loss of the binding signal over the same time. Of the two phases of formate binding shown by our fast oxidase preparations [5], the fast phase is lost completely, whereas $\sim 20 \%$ of the slow phase remains after 180 min incubation with $0.5 \mathrm{M} \mathrm{Cl}^{-}$. Prolonged incubation ( $>4-5 \mathrm{~h}$ ) leads to the complete loss of detectable formate binding (results not shown). Like fast enzyme that has been incubated with $\mathrm{CO}_{2} / \mathrm{HCO}_{3}{ }^{-}$, enzyme that has been incubated with $\mathrm{Cl}^{-}$shows no reactivity towards $\mathrm{CO}$ in the presence of oxygen (results not shown).

\section{$\mathrm{Cl}^{-}$-ligated form present in cytochrome $\mathrm{C}$ oxidase as prepared}

The method described by Brandt et al. [8] for the preparation of fast cytochrome oxidase involves the use of high concentrations of $\mathrm{Cl}^{-}$at several stages. We have found that some preparations made using this method show a phase of cyanide binding with intermediate kinetics (Figure 6). The rate constant for this phase is clearly $\mathrm{pH}$-dependent (results not shown), in the same way as the rate constant for the intermediate phase of cyanide binding induced by incubation of fast oxidase with $\mathrm{Cl}^{-}$[5]. The extent of the formate-binding signal shown by this preparation is small compared with that shown by the other preparation shown in Figure 6, which was made by the method of Moody et al. [5], and that which is seen equates with the fast phase of cyanide binding. Thus, by implication, the subpopulation responsible for the intermediate phase of cyanide binding shows no detectable formate binding, again consistent with the properties of the $\mathrm{Cl}^{-}$ligated enzyme.

\section{DISCUSSION}

In this paper we have shown that $\mathrm{CO}_{2} / \mathrm{HCO}_{3}{ }^{-}$induces a novel form of bovine heart cytochrome $c$ oxidase. This form binds cyanide at a rate intermediate between those of the fast and slow forms of the enzyme $\left(0.2 \mathrm{M}^{-1} \cdot \mathrm{s}^{-1}\right.$ compared with $1-2 \mathrm{M}^{-1} \cdot \mathrm{s}^{-1}$ and $0.01-0.02 \mathrm{M}^{-1} \cdot \mathrm{s}^{-1}$ for the fast and slow forms respectively). Since we have already observed the appearance of a form of the enzyme with similar cyanide-binding kinetics on incubation of cytochrome oxidase with $\mathrm{Cl}^{-}$[5], the question immediately arises: is the form induced by $\mathrm{CO}_{2} / \mathrm{HCO}_{3}{ }^{-}$the same as that induced by $\mathrm{Cl}^{-}$? The answer to this seems to be no, because, as we show here, the form induced by $\mathrm{CO}_{2} / \mathrm{HCO}_{3}^{-}$has several features that make it distinct from the form induced by $\mathrm{Cl}^{-}$(Table 1).

One major difference is that the Soret absorption maximum of the $\mathrm{CO}_{2} / \mathrm{HCO}_{3}{ }^{-}$form is close to $427 \mathrm{~nm}$ and hence is red-shifted relative to that of the fast form of the enzyme, which has a maximum at $424 \mathrm{~nm}$, whereas the Soret band of the $\mathrm{Cl}^{-}$-induced form is, if anything, slightly blue-shifted [5]. For the following reasons, we propose that the red shift in the Soret band induced by $\mathrm{CO}_{2} / \mathrm{HCO}_{3}^{-}$is due to haem $a_{3}$ rather than haem $a$. Haem $a_{3}$ in fast oxidase appears to have a split Soret band, with one component at $\sim 414 \mathrm{~nm}$ and another at $\sim 428 \mathrm{~nm}$, whereas haem $a$ has a single band at $\sim 428 \mathrm{~nm}$. We had suggested that a mixture of the high- and low-spin states of haem $a_{3}$ is present in the fast form of the enzyme, and that haem $a_{3}$ goes completely high-spin when formate binds (with $\lambda_{\max } 417 \mathrm{~nm}$ ) or completely low-spin when cyanide binds (with $\lambda_{\max } 428 \mathrm{~nm}$ ) [5]. However, a recent suggestion that there is a mixture of high- and intermediatespin haem $a_{3}$ in fast oxidase [17] provides a better explanation, which is consistent with earlier magnetic c.d. and resonance Raman data $[18,19]$. Nevertheless, the notion of a split Soret band is still valid. If the red shift induced by $\mathrm{CO}_{2} / \mathrm{HCO}_{3}{ }^{-}$is due to an increase in the intensity of the ' $428 \mathrm{~nm}$ ' band of haem $a_{3}$, at the expense of the ' $414 \mathrm{~nm}$ ' band, then we expect $\Delta \epsilon_{432-412}$ (or $\left.\Delta \epsilon_{428-410}\right)$ when cyanide binds to $\mathrm{CO}_{2} / \mathrm{HCO}_{3}{ }^{-}$-treated enzyme to be smaller than that found for the control enzyme. In fact, we expect $\Delta \epsilon_{432-412}$ to be approximately halved because $\Delta \epsilon_{432-412}$ for the $\mathrm{CO}_{2} / \mathrm{HCO}_{3}^{-}$-induced change at $28 \mathrm{mM}^{-1} \cdot \mathrm{cm}^{-1}$ (Figure 1) is about half that $\left(50 \mathrm{mM}^{-1} \cdot \mathrm{cm}^{-1}\right)$ for cyanide binding to fast enzyme. This is indeed what is seen (Figures 2 and 3). However, if the red shift induced by $\mathrm{CO}_{2} / \mathrm{HCO}_{3}{ }^{-}$were due to haem $a$ we would expect no decrease in $\Delta \epsilon_{432-412}$, and, furthermore, the isosbestic point for the shift would be $>428 \mathrm{~nm}$ rather than $424 \mathrm{~nm}$ (Figure 1). In contrast, $\mathrm{Cl}^{-}$-treated enzyme, which does not have a red-shifted Soret band, binds cyanide with essentially the same $\Delta \epsilon_{432-412}$ as control enzyme [5].

Other differences between the $\mathrm{CO}_{2} / \mathrm{HCO}_{3}^{-}$- and $\mathrm{Cl}^{-}$-induced forms of cytochrome oxidase relate to their ligand-binding kinetics. The rate of cyanide binding to $\mathrm{Cl}^{-}$-treated enzyme is markedly $\mathrm{pH}$-dependent, increasing 3-fold between $\mathrm{pH} 6.5$ and 8.0 , but this is not the case for $\mathrm{CO}_{2} / \mathrm{HCO}_{3}{ }^{-}$-treated enzyme. It may also be that formate binding to $\mathrm{CO}_{2} / \mathrm{HCO}_{3}{ }^{-}$-treated enzyme, though slow, is detectable, since loss of the two phases of binding associated with fast enzyme seems to be associated with the appearance of a new phase of binding (Figure 3), whereas enzyme that has been treated at $\mathrm{pH} 6.5$ with $0.5 \mathrm{M} \mathrm{Cl}^{-}$for 4-5 h lacks any detectable formate binding (results not shown).

It is clear, therefore, that $\mathrm{CO}_{2} / \mathrm{HCO}_{3}{ }^{-}$induces a novel form of cytochrome oxidase. However, the identity of the bound species $\left(\mathrm{CO}_{2}, \mathrm{H}_{2} \mathrm{CO}_{3}\right.$ or $\left.\mathrm{HCO}_{3}^{-}\right)$and of its binding site are unknown. Given the general lowering of the reactivity of the binuclear centre (binding of both cyanide and formate is inhibited, as are the reactions with $\mathrm{H}_{2} \mathrm{O}_{2}$ and $\mathrm{CO}$ in the presence of $\mathrm{O}_{2}$ ), it is likely that the binding site is close to the binuclear centre, although the 
observation of a spectral shift in haem $a_{3}$ does not necessarily imply that the site directly involves the haem iron. The binding appears to be tight, since the effects of incubation with $\mathrm{CO}_{2}$ / $\mathrm{HCO}_{3}{ }^{-}$are retained after removal of the excess by passing the enzyme down a Sephadex G-25 column, but it is still possible that there is no tightly bound species and that the presence of $\mathrm{CO}_{2} / \mathrm{HCO}_{3}{ }^{-}$triggers a change in the conformation of the binuclear centre that is retained in its absence. This latter possibility would seem more likely if $\mathrm{Cl}^{-}$and $\mathrm{CO}_{2} / \mathrm{HCO}_{3}{ }^{-}$had identical effects on the enzyme, but the fact that their effects are only broadly similar suggests instead that they have a common tight binding site.

Phases of cyanide binding with intermediate kinetics have been seen by others in cytochrome oxidase as prepared $[4,20]$, and so it is worth considering whether these could be caused by the presence of the $\mathrm{CO}_{2} / \mathrm{HCO}_{3}{ }^{-}$-ligated enzyme. However, at least in one case where we have observed a cyanide-binding phase with intermediate kinetics, i.e. in preparations made by the method of Brandt et al. [8] (Figure 6), it seems certain, in agreement with Lodder [21], that this is caused by the presence of the $\mathrm{Cl}^{-}$-ligated form. Nevertheless, high levels of the $\mathrm{CO}_{2} / \mathrm{HCO}_{3}{ }^{-}$-induced form are certainly found after storage of the enzyme overnight in solid $\mathrm{CO}_{2}$, unless it is kept in a gas-tight container. With the recent interest in the various members of the superfamily of terminal oxidases that contain $\mathrm{Cu} / \mathrm{Fe}$ binuclear centres [22] and to which mammalian cytochrome $c$ oxidase belongs, it has become common practice to transport enzyme samples between laboratories, and often the only practical way to do this is by packing the samples in solid $\mathrm{CO}_{2}$. If other members of the superfamily are modified by storage in solid $\mathrm{CO}_{2}$ in a similar way to mammalian cytochrome $c$ oxidase, then this could lead to confusion about the characteristics of these enzymes, and in particular their ligand-binding properties. Hence, we advise the precautionary use of gas-tight containers for storage of such samples in solid $\mathrm{CO}_{2}$.

Both $\mathrm{CO}_{2} / \mathrm{HCO}_{3}{ }^{-}$and $\mathrm{Cl}^{-}$clearly decrease the reactivity of the binuclear centre, but they do not impede intramolecular electron transfer from haem $a$ to the binuclear centre, unlike the putative endogenous ligand present in the slow form of the enzyme [5]. The physiological concentrations of both $\mathrm{CO}_{2} / \mathrm{HCO}_{3}{ }^{-}$and $\mathrm{Cl}^{-}$ are probably millimolar or greater [23], and so both could be ligands in vivo. However, it appears that both $\mathrm{CO}_{2} / \mathrm{HCO}_{3}{ }^{-}$and $\mathrm{Cl}^{-}$must be displaced during turnover because if this were not the case it would not be so simple to prepare cytochrome oxidase that is wholly in the fast form [4,5]. It follows that both $\mathrm{CO}_{2} / \mathrm{HCO}_{3}^{-}$and $\mathrm{Cl}^{-}$are probably ineffective as inhibitors of cytochrome oxidase.

This work was funded by the Glynn Research Foundation Ltd. M.R. and J.P.E.S were recipients of the 1993 and 1992 Peter Mitchell Summer Studentships respectively. We are grateful to Simon Brown and Roy Mitchell for helpful discussions, and to Robert Harper and Sally Madgwick for technical help.

\section{REFERENCES}

1 Babcock, G. T. and Wikström, M. (1992) Nature (London) 356, 301-309

2 Malmström, B. G. (1993) Acc. Chem. Res. 26, 332-338

3 Brudvig, G. W., Steven, T. H., Morse, R. H. and Chan, S. I. (1981) Biochemistry 20, 3912-3921

4 Baker, G. M., Noguchi, M. and Palmer, G. (1987) J. Biol. Chem. 262, 595-604

5 Moody, A. J., Cooper, C. E. and Rich, P. R. (1991) Biochim. Biophys. Acta 1059, 189-207

6 Antonini, G., Brunori, M., Colosimo, A., Malatesta, F. and Sarti, P. (1985) J. Inorg. Biochem. 23, 289-293

7 Schoonover, J. R. and Palmer, G. (1991) Biochemistry 30, 7541-7550

8 Brandt, U., Schägger, H. and von Jagow, G. (1989) Eur. J. Biochem. 182, 705-711

9 Yonetani, T. (1961) J. Biol. Chem. 236, 1680-1688

10 Cotton, F. A. and Wilkinson, G. (1966) Advanced Inorganic Chemistry, 2nd edn., pp. 308-309, Wiley Interscience, New York

11 CRC Handbook of Chemistry and Physics (1987) (Weast, R. C., Astle, M. J. and Beyer, W. H., eds.), 68th edn., p. B-82, CRC Press Inc., Boca Raton, FL

12 van Buuren, K. J. H., Nicholls, P. and van Gelder, B. F. (1972) Biochim. Biophys. Acta 256, 258-276

13 Nicholls, P. (1976) Biochim. Biophys. Acta 430, 13-29

14 Ebert, K., Ederer, H. and Isenhour, T. L. (1989) Computer Applications in Chemistry, $\mathrm{VCH}$, Weinheim

15 Vygodina, T. V. and Konstantinov, A. A. (1988) Ann. N.Y. Acad. Sci. 550, 124-138

16 Morgan, J. E., Blair, D. F. and Chan, S. I. (1985) J. Inorg. Biochem. 23, 295-302

17 Day, E. P., Peterson, J., Sendova, M. S., Schoonover, J. and Palmer, G. (1993) Biochemistry 32, 7855-7860

18 Woodruff, W. H., Kessler, R. J., Ferris, N. S., Dallinger, R. F., Carter, K. R., Antalis, T. M. and Plamer, G. (1982) in Electrochemical and Spectrochemical Studies of Biological Redox Components (Kadish, K. M., ed.), pp. 625-659, American Chemical Society, Washington, DC

19 Schoonover, J. R., Dyer, R. B., Woodruff, W. H., Baker, G. M., Noguchi, M. and Palmer, G. (1988) Biochemistry 27, 5433-5440

20 Young, L. J. (1988) Biochemistry 27, 5115-5121

21 Lodder, A. L. (1993) Ph.D. Thesis, University of Amsterdam, Amsterdam

22 Saraste, M., Holm, L., Lemieux, L., Lübben, M. and van der Oost, J. (1991) Biochem. Soc. Trans. 19, 608-612

23 Masuda, T., Dobson, G. P. and Veech, R. L. (1990) J. Biol. Chem. 265 20321-20334 